\title{
TRADIÇÃO E MATEMÁTICA: A ETNOMATEMÁTICA DA CERÂMICA CAETEUARA DA VILA “CUÉRA" EM BRAGANÇA-PA
}

\author{
Samuel Antonio Silva do Rosario ${ }^{1}$ \\ Luis Junior Costa Saraiva ${ }^{2}$
}

\begin{abstract}
RESUMO
O presente artigo apresenta uma análise sobre relações entre a Matemática e a tradição de construção da cerâmica caeteuara. A pesquisa está sendo realizada em uma comunidade amazônica de características tradicionais, chamada "Vila Cuéra", situada no espaço rural do município de Bragança, Pará, Brasil, às margens do rio Caeté. A experiência retrata o processo de construção da cerâmica caeteuara, ressaltando aspectos importantes onde o ceramista se utiliza de uma racionalidade matemática própria para construir suas peças, transformando um pensamento abstrato em uma peça concreta. Objetivamos ressaltar cada saber envolvido no processo de fabricação, a qual relaciona os conteúdos matemáticos conhecidos como geometria e simetria ao saberes do ceramista. As práticas pertencentes aos saberes constituídos na tradição amazônica são atualizadas no cotidiano dos mestresartesãos presentes nessa região. A intenção deste trabalho é destacar a necessidade de diálogos entre saberes Etnomatemáticos com os conhecimentos científicos oriundos da Ciência Matemática, como uma rota para compreender e respeitar as várias formas de produzir conhecimento das diversas populações que compõem a Amazônia.
\end{abstract}

Palavras-chave: Tradição. Etnomatemática. Cerâmica Caeteuara.

\begin{abstract}
The present article is an information about the mathematics and the tradition of construction of caeteuara ceramics. A research is being conducted in an Amazonian community of classics, called "Vila Cuéra", located in the interior of the county of Bragança, Pará, Brazil, on the Caeté River. The experience portrays the process of construction of caeteu ceramics, highlighting the important aspects for ceramism if employed a mathematical rationality and the ability to highlight their pieces, transforming an abstract thought into a concrete piece. We aim to highlight each of the knowledge involved in the manufacturing process, a relation according to the mathematical patterns known as geometry and symmetry to the knowledge of the ceramist. The pieces belonging to the knowledge were constituted in the Amazonian tradition are updated in the daily life of the masters-artisans present in the region. This study is a high level of knowledge among clinical studies and scientific studies for the knowledge of the knowledge of the knowledge matter of the plural knowledge that compose the Amazon.
\end{abstract}

Keywords: Tradition. Ethnomathematics. Ceramics Caeteuara.

\footnotetext{
${ }^{1}$ Mestrando pelo Programa de Pós-Graduação em Linguagens e Saberes na Amazônia (UFPA). Membro dos grupos de pesquisa LELIM (Laboratório de Estudo Linguagem, Imagem e Memórias) e ETTHOS (Educação, Trabalho, Tecnologia, Humanidades e Organização Social).samuel_mat2009@hotmail.com

2 Doutor em Antropologia. Professor Adjunto FACED/UFPA, Campus de Bragança. Membro dos grupos de Pesquisa ESAC (Estudos Socioambientais Costeiros) e LELIM (Laboratório de Estudo Linguagem, Imagem e Memórias). luisjsaraiva@gmail.com.br
} 


\section{INTRODUÇÃO}

A comunidade "Vila Cuéra" está localizada no espaço rural do município de Bragança- $\mathrm{Pa}$, às margens do rio Caeté, aproximadamente oito quilômetros do centro da cidade, à esquerda da BR 308 (Im 1). A comunidade faz parte da história da construção do município, pois segundo a história oficial contada nos livros e pelos próprios moradores locais, foi neste espaço que iniciou anos atrás o que hoje conhecemos como município de Bragança, por este motivo a comunidade é conhecida também como "Vila Que Era" Bragança $(\operatorname{Im} 2)$.

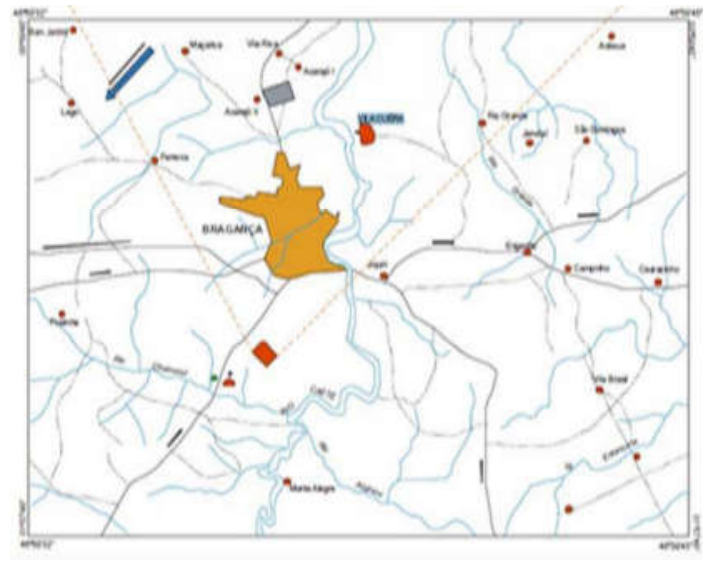

Im 2 Fonte - Acervo pessoal

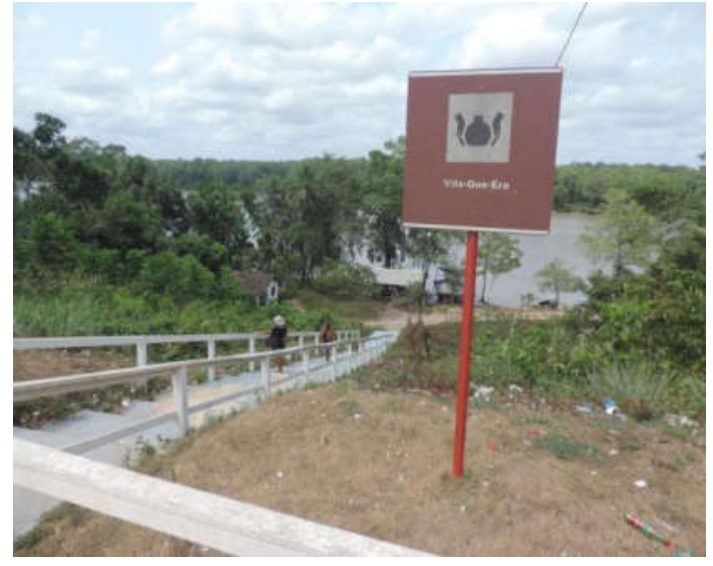

Im 1 Fonte - Acervo pessoal

Nesse espaço permanece a memória de um lugar que sediou a primeira Vila referente à cidade de Bragança e que ainda guarda em seu nome o significado desse período. Conhecendo um pouco mais da historia da vila é possível perceber que em alguns momentos que a história da vila na verdade é parte de uma história nacional, como relata a autora Tavares (1998, p. 12,13):

Em 9 fevereiro de 1622, Felipe III, rei da Espanha, doou a Capitania, através de carta régia, ao governador do Brasil, Gaspar de Souza que, em 9 de junho desse mesmo ano, fez presente desses territórios a seu filho, Álvaro de Souza.

Em 1633, Francisco Coelho de Carvalho doou a mesma Capitania a seu filho, Feliciano Coelho de Carvalho, cuja sede teve a denominação de vila de Vera Cruz, às margens do rio Piriá, território dos índios Apotiangas, da nação Tupinambá.

Álvaro de Souza, filho de Gaspar de Souza, recorreu à corte de Madri, já que Portugal pertencia à Coroa Espanhola, reclamando direitos sobre a Capitania. A coroa anulou o ato de doação de Francisco Coelho de Carvalho a seu filho e, através de carta régia de 13 de fevereiro de 1634, confirmou o direito de posse ao reclamante. 
Para desenvolver a Capitania, Álvaro de Souza instalou sua sede na margem direita do rio Caeté, fundando o povoado denominado de vila Souza do Caeté, atualmente conhecida como vila Cuéra ou Qui-Era. Com uma população quase que exclusivamente indígena pouco prosperou. Transformado em freguesia, ressurge com o nome de Nossa Senhora do Rosário de Bragança.

Em 1754, Francisco Xavier de Mendonça Furtado, governador e capitão mór do Estado do Maranhão e Grão-Pará, visitou Souza do Caeté e achou o local pouco desenvolvido. Resolveu, então, dar-lhe novo impulso elevando-o à categoria de vila, e ao transferi-lo para a margem esquerda do rio Caeté, para o local onde, hoje, é o bairro da Aldeia da atual sede municipal.

Hoje a Vila é conhecida por alguns por Vila "Cuera" e por outros como Vila "Que era", e esse dilema contido no nome da vila pode ser verificado durante o levantamento sociocultural da comunidade realizado durante a pesquisa. No decorrer do levantamento podemos registrar que parte dos moradores mais velhos prefere o nome de vila "Cuera" mesmo sem conhecer o real significado desde nome, porém com maior receptividade por questões históricas. Já outra parcela em comum acordo com os mais novos da comunidade prefere o nome de vila "que era", pois entende o significado de que aquela comunidade foi Bragança no passado, diferente de Cuéra que não apresenta um significado definido para a maioria.

Conhecendo um pouco mais a Vila e seu dia a dia como organismo vivo e dinâmico foi possível encontrar um conjunto de saberes e atividades realizadas pelos moradores que envolvem os diversos ambientes da comunidade ${ }^{3}$, como: pesca, agricultura, artesanato, pajelança. Encontramos ainda: parteiras, pais de santo, comerciantes, professores etc.

Nesse contexto apresentado, cabe ressaltar que a pesquisa aconteceu mais precisamente com uma dessas famílias, a família Furtado que desenvolve o oficio de fabricação de peças de barro há gerações, mantendo particularidades que serão mais bem exploradas no decorrer deste trabalho.

Apesar do desenvolvimento da pesquisa ser em torno de uma família, o dia a dia na comunidade nos permitiu contemplar outros momentos importantes tanto para a história da comunidade, como para a história cultural do município de Bragança-Pa.

A vila agrega diversos saberes nas muitas atividades desenvolvidas por seus habitantes, que despertam a curiosidade de conhecer e de entender as dinâmicas que regem as sabedorias expostas no cotidiano em comunidade. E é focando em um desses saberes que esse trabalho se pautará, mais especificamente na construção da cerâmica caeteuara da comunidade, uma atividade repleta de conhecimentos etnomatemáticos.

\footnotetext{
${ }^{3}$ O levantamento sociocultural é resultado do trabalho de três pesquisadores Jéssica Leite, Luis Saraiva e Samuel Silva que ainda está em processo de publicação e finalização da cartografia social da comunidade, que registra aspectos importantes da localidade a partir dos moradores.
} 


\section{CERÂMICA CAETEUARA}

A cerâmica caeteuara traz em seus traçados elementos que ajudam a montar a história da própria região, a maneira como é feita, desde a escolha da argila até o produto final, possui particularidades encontradas apenas nesse saber-fazer.

A família Furtado, uma das poucas que ainda mantém a tradição de construir peças a partir da argila na região, exibe com orgulho peças com mais de 100 anos (Im 3) e conta como o ofício foi sendo passado entre as gerações familiares, legado histórico deixado por familiares que já se foram desse mundo material, mas que ainda continuam presentes nas memórias expressas em cada uma das peças.

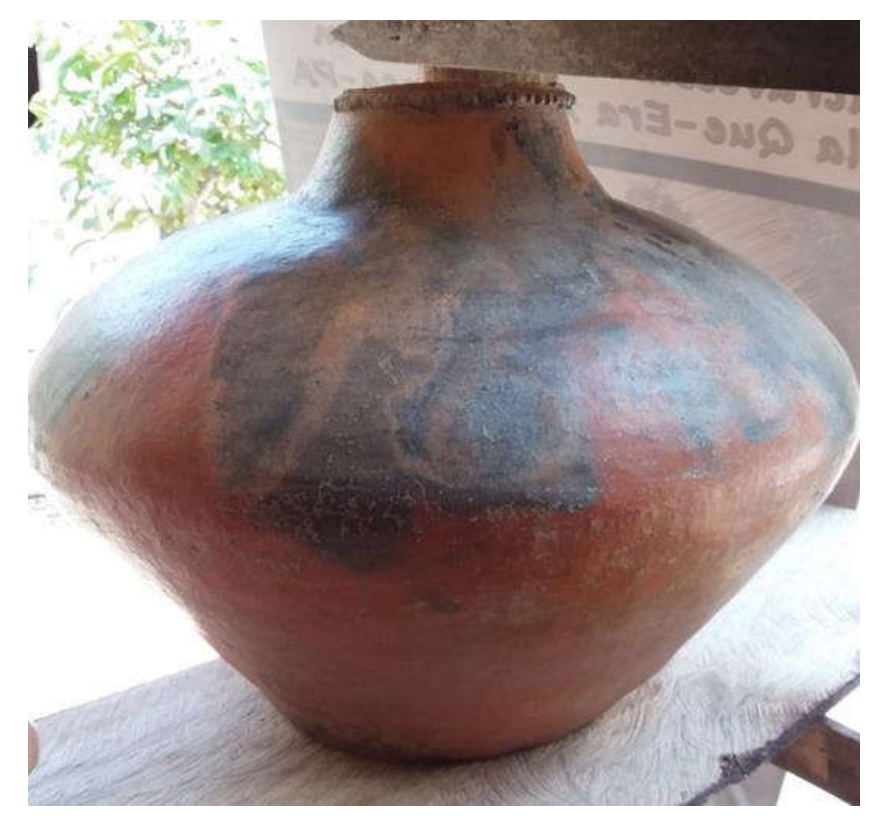

Im 3 Fonte - Acervo pessoal

A forma de fazer cerâmica com caráter caeteuara é uma forma simbólica de demonstrar a relação direta que os ceramistas dessa região têm com o rio caeté. O lugar de onde é retirada a argila que dá origem ao processo de construção da cerâmica caeteuara geralmente se encontra às margens do rio caeté onde só é possível se chegar de canoa, com uma dinâmica de retirada da argila funcionando de forma alternada, visando a sustentabilidade do oficio. A ceramista chamada Maria explica que essa foi uma forma encontrada por sua família para que sempre tivesse argila disponível. 
A gente atravessa de canoa e pega ela em algum lugar ai do rio, geralmente só de olhar a argila, eu já sei qual presta, desse jeito eu conheço vários lugares onde tem a argila que eu preciso. E é incrível, quando a gente tira a argila de um lugar, fica um buracão. mas quando a gente volta já está tudo recuperado, e da natureza mesmo (Informação verbal).

Essa rotina de retirada da argila da margem do rio caeté, geralmente acontece uma ou duas vezes por mês. Após escolher o lugar de coleta, existe um processo de seleção muito bem aprimorada por essa família, com suas particularidades e saberes. A família Furtado escolhe suas argilas a partir do visual, do tato e paladar. O ceramista Josisas argumenta que:

Primeira coisa para escolher a argila é eu está presente, com mais que eu peça pra alguém cavar, eu tenho que está lá presente pra saber (...). A questão visual já diz muito, pois pela cor eu já sei se ela presta e pra qual tipo de peça posso usar. (...) Depois que a cor me agrada, eu pego e vejo a consistência com a minhas mãos e logo depois ponho na boca, porque se tiver muito salgada não presta. (...) As vezes eu pego assim mesmo e trago pra casa, aqui ponho de molho para tirar o excesso de sal (Informação verbal).

A cerâmica caeteuara produzida na comunidade da "Vila Cuera", no município de Bragança-Pa, é dotada de uma beleza estética e geométrica sem igual, que serão tratados com muito cuidado e atenção no decorrer desse artigo. E essa estética e geometria são expressas na sabedoria popular com uma beleza que "enche os olhos de quem faz e de quem ver" e "dá orgulho pra quem faz". O processo de fabricação é manual e a transmissão do conhecimento ocorre por meio da tradição oral, pois nas comunidades tradicionais os conhecimentos que permeiam entre os variados saberes são passados de maneira empírica pela oralidade e através da vivência dos agentes sociais envolvidos, respeitando uma escala de gerações, assim uma geração mais experiente troca conhecimentos com a geração mais nova, onde a oralidade precede e sustenta a racionalidade, é a partir deste laço que ciência e tradição se cruzam, se reconhecem (Vergani, 2002) e este conhecimento encontra-se ameaçado de extinção, visto que apenas a família Furtado desenvolve esse oficio na comunidade.

A família Furtado desenvolveu algumas particularidades para produzir a cerâmica caeteuara, em um diálogo realizado em campo em 2017, o ceramista Josias nos explicou um pouco dessa particularidade:

Tudo começa na escolha da argila, a argila é tirada aqui da margem do rio caeté, a gente vai de canoa até o barreiro e traz pra cá, ai depois a gente vamo pegar essa argila e vamo usar os materiais que vão ser acrescentadas nessa mistura que é pra ela se tornar uma panela retratada, porque se não tiver essas misturas ela não vai segurar o fogo e vai rachar.(...) Aí a gente usa o caripé que é a casca de uma árvore, que nós estamos tendo dificuldade de encontrar hoje em dia, pelo desmatamento e a taicica 
que é a lagrima da árvore, nós usa só um tanto de uma árvore e deixa, pra não morrer.

Eu mesmo tiro o barro, mesmo que eu peça pro cara cavar, eu mesmo tenho que tá lá presente pra saber, é uma questão visual, eu escolho a argila, primeiro olhando, se a cor agradar, eu provo também, porque se tiver com muito sal não presta, aí tem outra técnica de pedir pra mãe do barro, aí é só deixar uma peça pra ela lá no rio que as todas as peças ficam boa (Informação verbal).

Assim os saberes envolvidos na produção da cerâmica caeteuara foram desenvolvidos a partir das experiências diárias, levando em consideração os sentidos do ceramista como instrumento principal de modelagem dessa racionalidade, assim, a visão, o paladar e tato, representam uma trindade de sentidos que auxiliam na permanência dessa tradição cultural.

\section{ETNOMATEMÁTICA}

Ao pensar em Matemática sempre se imagina algum conteúdo estudado no espaço escolar, algo complexo e difícil, mas a matemática está em toda a parte, inclusive no nosso corpo, basta olhar para o número dos dedos das mãos e as inúmeras vezes que são utilizados para somar ou diminuir pequenas quantidades. Esse recuso é uma ferramenta de extrema importância nas comunidades de características tradicionais, pois a relação estabelecida entre o corpo (concreto) e quantidade (abstrata) estão diretamente relacionadas e interligadas, ajudando a racionalizar necessidades específicas de cada grupo social.

Levando em consideração que a matemática surge a partir das necessidades de cada povo, cada grupo social desenvolve sua própria linguagem matemática que como qualquer outra forma de linguagem, carrega consigo uma visão de mundo, que determina a maneira de perceber e conceber a realidade, ajudando a concretizar o abstracionismo presente no modo de sentir o mundo (FIORIN, 1998).

A própria história nos mostra que diversas sociedades desenvolveram seus próprios sistemas de conhecimento diversificados usando para isto métodos de comparação, quantificação, medição e representação em alguma medida, semelhantes aos métodos conhecidos como matemáticos (Gerdes, 2014).

Assim, ao construir e estabelecer as bases da Etnomatemática centrada num enfoque abrangente da história das ciências, com abordagem na cognição e cultura, D'Ambrosio (1998) propôs um programa de pesquisa diferenciado em relação à matemática, reconhecendo-a como uma dinâmica cultural (ROSA; OREY, 2014) onde “(...) a matemática assume cognitiva e explicitamente o seu caráter transdisciplinar no seio de uma experiência reconhecidamente antropológica" (VERGANI, 2007, p. 24). O Programa Etnomatemática 
propõe o diálogo entre distintas concepções matemáticas, integrando cognição, história, sociologia do conhecimento e epistemologia social possibilitando uma dinâmica entre o saber e o fazer de diferentes culturas.

Para D'Ambrosio (2010) a etnomatemática busca entender ao longo da história da humanidade o saber-fazer. Nessa ideia há também em sua concepção histórica ciclos dos quais são necessários ao conhecimento, onde tais ciclos são os da geração, organização intelectual, organização social e difusão de conhecimento.

D’Ambrosio propõe o Programa Etnomatemática o qual "tem como referências categorias próprias de cada cultura, reconhecendo que é próprio da espécie humana a satisfação de pulsões de sobrevivência e transcendência, absolutamente integrados, como numa relação de simbiose" (2010, p. 45).

Segundo o autor:

etno é hoje aceito como algo muito amplo, referente ao contexto cultural, e portanto, inclui considerações como linguagem, jargão, códigos de comportamento, mitos e símbolos; matema é uma raiz difícil, que vai na direção de explicar, de conhecer, de entender; e tica vem sem dúvida de techne, que é a mesma raiz de arte e de técnica. Assim, poderíamos dizer que etnomatemática é a arte ou a técnica de explicar, de conhecer, de entender nos diversos contextos culturais (D’Ambrosio, 1998, p. 5).

Nessa perspectiva (D’AMBROSIO, 1993, p. 7), considera a Etnomatemática como um “(...) programa que visa explicar os processos de geração, organização e transmissão de conhecimento em diversos sistemas culturais e as forças interativas que agem nos e entre os três processos.".

E buscando conceituar o que viria ser a Etnomatmática, Barton (2004), argumenta que trata-se de uma pesquisa em que se busca compreender como determinados grupos culturais articulam conceitos matemáticos, mesmo não tendo um conceito de matemática formal.

Gerdes $(1989$, p.2) conceitua que "a Etnomatemática tenta estudar a Matemática (ou ideias matemáticas) nas suas relações com o conjunto da vida cultural e social", sendo um movimento motivado por objetivos sócio-políticos determinados e um campo de pesquisa por meio do qual é estudada a Matemática e suas relações com a vida cultural e social de determinados grupos.

Para Ascher (1986) a Etnomatemática é o estudo das ideias matemática de povos com baixa escolarização, onde por meio de um trabalho antropológico, a autora intenciona apelar a um trabalho etnográfico.

Knijnik (2008, p, 3) considera a Etnomatemática como uma caixa de ferramentas: "que nos possibilita estudar os discursos eurocêntricos que instituem as matemáticas 
acadêmica e escolar, analisando os efeitos de verdade produzidos por tais discursos e também examinar os jogos de linguagem que constituem diferentes matemáticas (...)”

Para Ferreira (1991) a Etnomátematica é vista como a matemática praticada por diferentes grupos culturais, sendo que cada grupo cultural produz sua própria Matemática de acordo com as suas necessidades de sobrevivência.

O Programa Etnomatemática, como elaborado por Ubiratan D’Ambrosio (2009) recebeu ao longo dos anos contribuições em suas diferentes dimensões, dependendo do contexto e do pesquisador responsável, agregou aspectos distintos, porém Miarka (2011) elenca três aspectos importantes para a pesquisa em Etnomatemática: o respeito ao outro, a presença do diálogo e a importância do conhecimento da língua do grupo cultural estudado.

Desse modo, a Etnomatemática deriva do pressuposto de que sociedade, cognição e cultura estão interligadas, ou seja, "a matemática é uma atividade universal, é uma atividade pancultural e pan-humana. Em todas as culturas o pensamento matemático tem tido lugar, tanto duma maneira espontânea como duma maneira organizada (...)" (GERDES, 2010, p. 159), com base na relação entre estes três eixos é que a Etnomatemática se constitui como campo de investigação e como proposta de uma educação múltipla e universalizante (FARIAS, C.; MENDES, 2014), correspondendo à proposição de que existe a necessidade de um conhecimento matemático local tanto quanto o conhecimento matemático global, ou seja: “(...) a Etnomatemática desenvolveu formas de conhecer e analisar as diversas epistemologias matemáticas operando nos seus contextos culturais" (MOREIRA, 2008, p.6).

Nessa perspectiva, utilizamos a etnomatemática nesta pesquisa como forma de respeitar as outras racionalidades matemáticas existentes, dialogando com os intelectuais do saber que praticam a tradição de construir peças de barro, dando a real importância à forma pela qual o ceramista explica seu "Etnoconhecimento".

\section{SABERES ETNOMATEMÁTCOS PRESENTES NO PROCESSO DE CONSTRUÇÃO DA CERÂMICA CAETEUARA}

A produção da cerâmica caeteuara é rica em saberes, sua construção nos leva a buscar um outro olhar sobre a cerâmica, de tal forma que nos permita entender suas figuras e formas. Dentro dessa perspectiva buscamos observar todo o processo de construção da cerâmica, desde o pensamento dos ceramistas até a peça já concretizada no barro.

Durante a pesquisa acompanhamos uma família que ainda mantém a tradição de construir peças de barro como já foi citado no início deste artigo, porém, para termos uma 
lógica estrutural nesse trabalho adotaremos o nome de Dona Maria para a mãe (que ainda produz suas peças através da fogueira) e Josias para o filho (que produz suas peças no forno à lenha).

Dona Maria ainda produz suas peças de maneira artesanal com processos rudimentares aprendidos com sua mãe, que anteriormente aprendeu com a vó e assim sucessivamente. Dona Maria comentou em um diálogo em campo que:

Essa cultura é muito antiga, muito antiga mesmo, quando eu me criei ela já existia, não era só da minha mãe, outras mulheres também sabiam fazer, mas hoje só a gente faz. Aos poucos as mulheres foram parando e restou só eu (2017, Informação verbal)

Assim, ela constrói suas peças de maneira tradicional e manual, sem ajuda de muitas ferramentas constrói peças de diversos formatos e com simetria quase perfeita. Partindo de um material bruto que é a argila (Im 4), transformando-a em uma pequena esfera com suas próprias mãos e por fim em uma peça tridimensional ( $\operatorname{Im} 5$ e $\operatorname{Im} 6$ ) com formas simétricas bem colocadas, resultados de anos de prática.

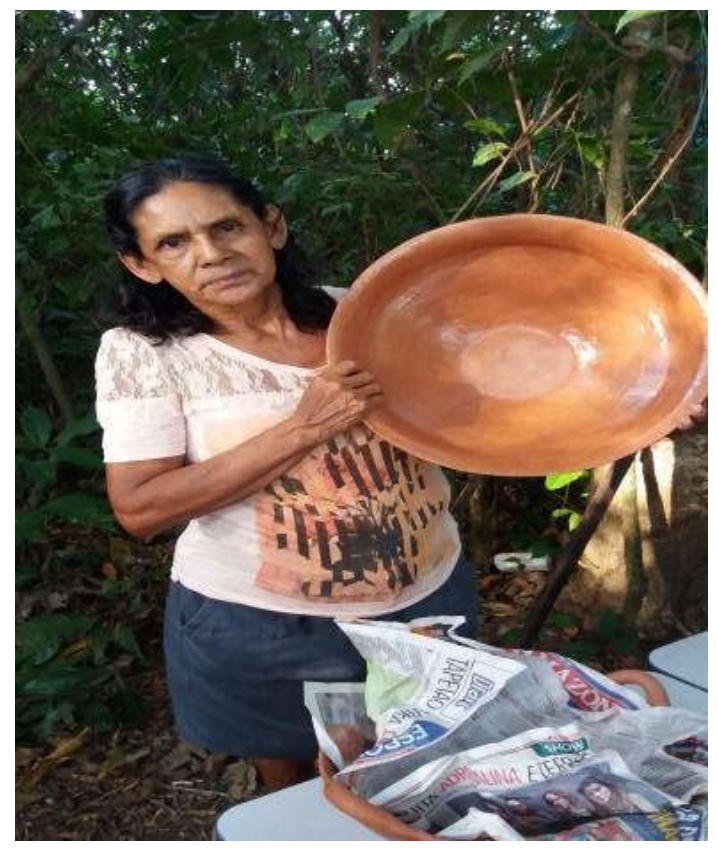

Im 4 Fonte - Acervo pessoal

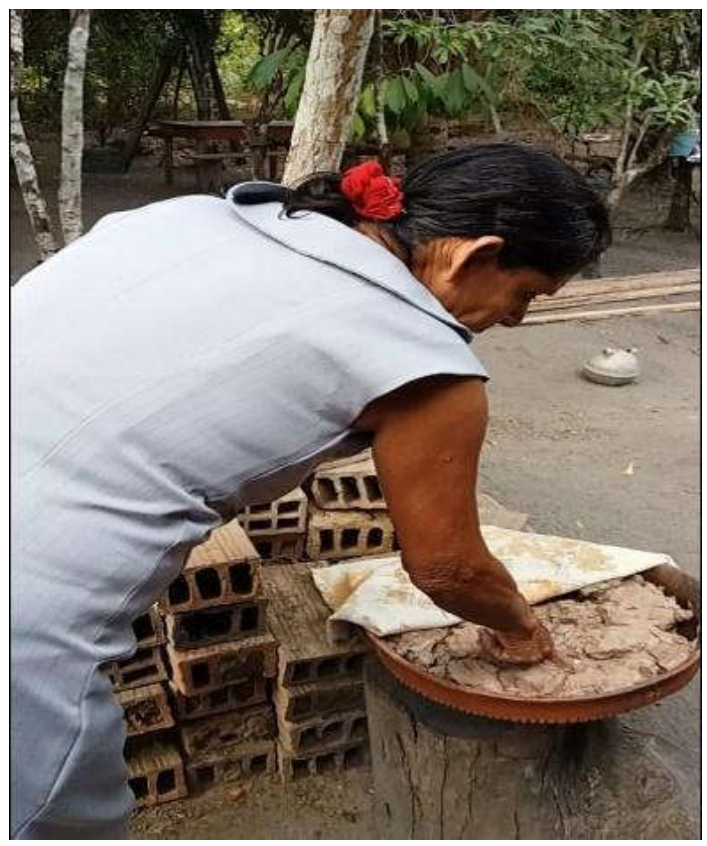

Im 5 Fonte - Acervo pessoal 


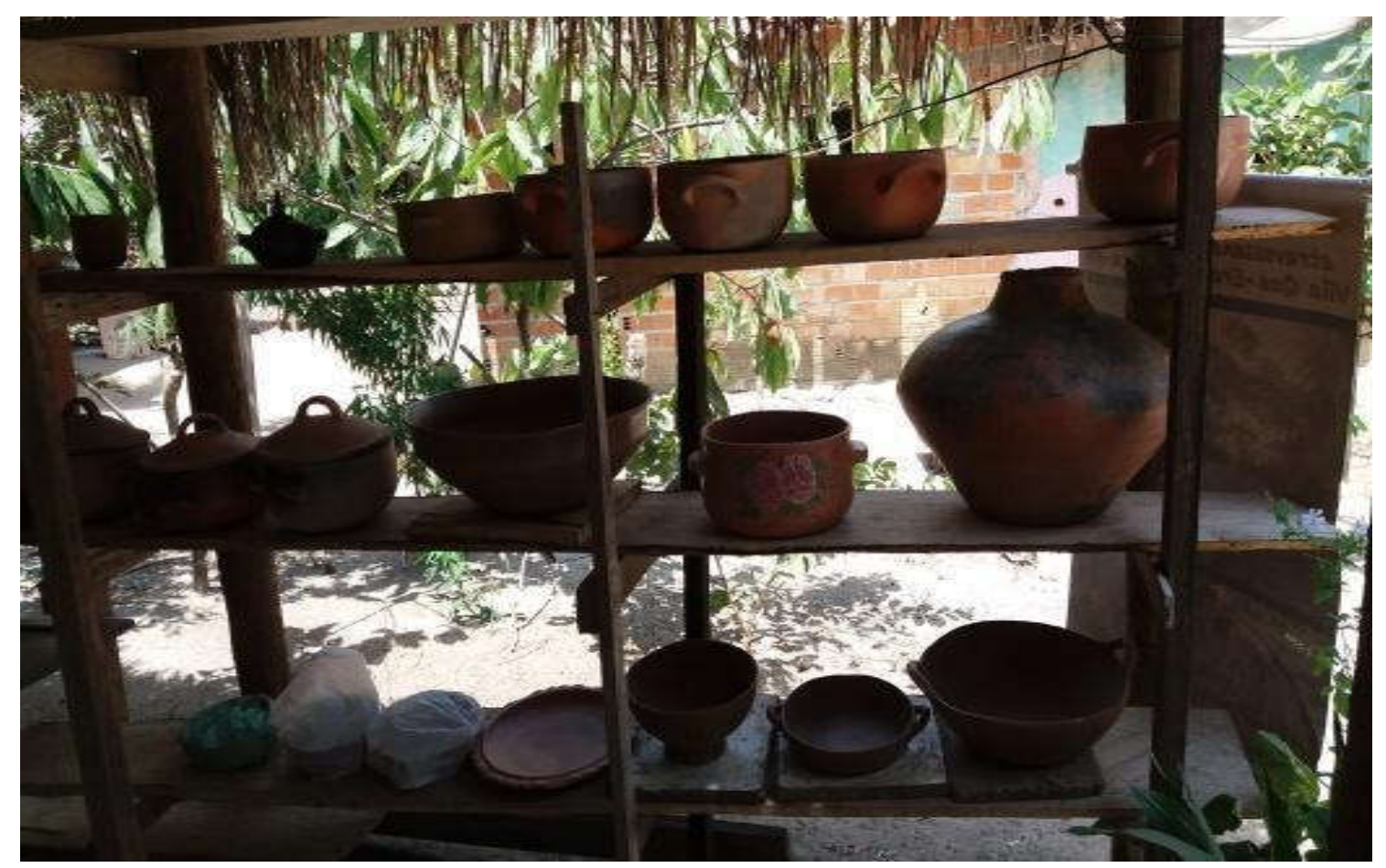

Im 6 Fonte - Acervo pessoal

Durante a pesquisa com dona Maria, foi possível observar que suas peças priorizam formas circulares, esféricas e cilíndricas nos arremetendo aos conceitos de círculo, corpos arredondados e de cilindros vistos na geometria tradicional acadêmica. Porém, dona Maria argumenta que costuma dar forma arredondada para suas peças seguindo uma outra lógica geométrica, onde a praticidade do cotidiano é prioridade, o que a levou utilizar a melhor estrutura que pudesse auxiliar em seu oficio, "pois essa foi a forma que eu aprendi com minha mãe, primeiro a gente faz uma bolinha e depois vai dando forma a peça, essa forma, vem da minha cabeça mesmo, já tenho dentro de mim" (Dona Maria, 2017, Informação verbal). Dessa maneira, começamos a entender que na verdade essa racionalidade matemática desenvolvida por dona Maria e sua família é totalmente baseada na vida prática, visto que para dar forma e dimensões à peça de barro é preciso um trabalho artesanal do pensamento, onde pensamento e argila são reais ao ponto de um refletir a concretude do outro, tornando real a peça final e mantendo esse saber etnomatemático relacionado à tradição.

Almeida (2010, p. 67) conceitua que "diferentemente do senso comum, os saberes da tradição arquitetam compreensões com base em métodos sistemáticos, experiências controladas e sistematizações reorganizadas de forma contínua”.

Nesse sentido, dona Maria não só expressa saberes etnomatemáticos através do seu ofício, mas também os constrói através de suas experimentações diárias, fazendo justo o 
conceito de intelectual do saber. Suas peças são construídas a partir de uma sistematização própria que foi aprimorada com o passar dos anos.

Durante a pesquisa de campo também tivemos contato com o ceramista Josias que é filho de dona Maria e que também constrói peças de argila, porém Josias desenvolveu métodos diferenciados para seu ofício, dando novas formas e dimensões para a cerâmica caeteuara.

Em um diálogo em campo realizado em 2017 o ceramista nos explicou como suas peças são criadas e de onde vem a inspiração para criar suas obras:

(...) Às vezes eu sonho e quando acordo vou cedinho pra oficina, pego o barro e faço a peça, algumas dificuldades que aparecem na peça as vezes eu tiro no sonho, mas elas sempre saem certinho, o tamanho que é de um lado, também é do outro. (...) $\mathrm{Na}$ hora de modelar eu gosto de trabalhar com círculos, triângulos e quadrados, pois são mais fácil de modelar, mas agora estou fazendo com outros formatos, de peixe, de barco e até de bicho, ai eu uso outras figuras, algumas eu nem conheço, mas vi em algum lugar. (...) a quantidade de barro que leva cada peça, eu já sei de cabeça, só de pensar já consigo ver ela pronta, ai vou só montando com as minhas mãos, ai olhando eu sei se ela tá torta ou certinha.

É perceptível na fala de Josias que conceitos da Matemática acadêmica estão muito presentes em seu cotidiano como ceramista, mesmo de maneira empírica, ele consegue determinar figuras geométricas planas como triângulos, quadrados e círculos e espaciais como pirâmides, cilindros e esferas. Mesmo desconhecendo conceitos e termos próprios da Matemática científica, suas peças possuem formas extremamente bem elaboradas.

O ceramista Josias costuma criar peças de formatos e dimensões variadas e para isso desenvolveu formas em gesso e também em madeira para ajudar na modelagem de suas peças, como por exemplo a sequência de imagem (Im 7, $\operatorname{Im} 8$ e $\operatorname{Im}$ 9) que mostra algumas dessas formas modeladoras. Essas formas possuem estruturas criadas pelo próprio ceramista que costuma dizer durante os diálogos em campo que "tudo que penso, gosto de construir com as mãos, não importa se é uma panela, um peixe, um cachorro, seu eu sonho consigo construir" (Josias, Informação verbal). E nesse sentido podemos entender a lógica que rege seu raciocínio geométrico onde as figuras planas são criadas primeiramente e, posteriormente, são dadas dimensões espaciais as mesmas. 


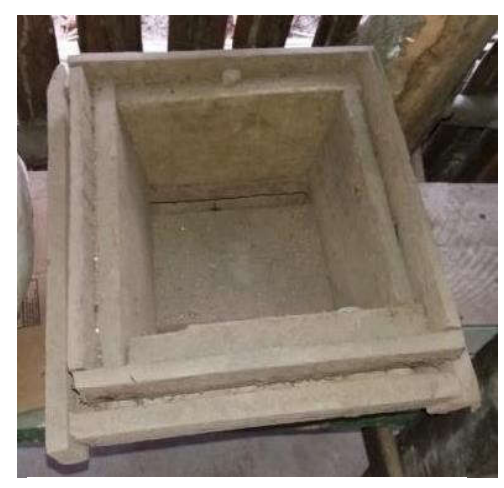

Im 7 Fonte - Acervo pessoal

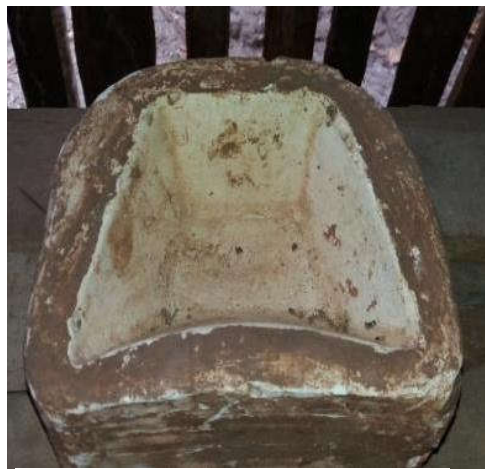

Im 8 Fonte - Acervo pessoal

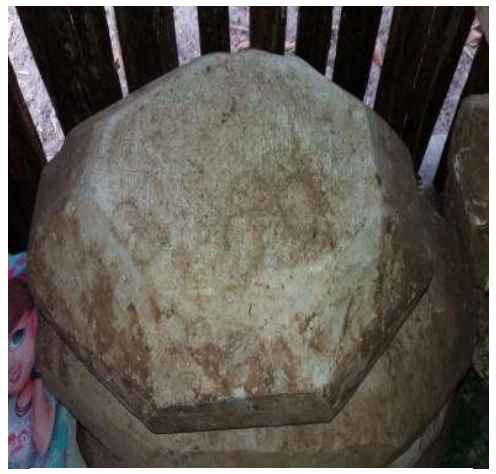

Im 9 Fonte - Acervo pessoal

O ceramista explica que utiliza essas formas para lhe ajudar na produção de peças de mesma dimensão, "ultimamente tenho recebido muitas encomendas de peças de mesmo tamanho, aí resolvi aprender a fazer essas formas pra mim ajudar" (Josias, Informação oral). Além dessas peças moldados na forma de gesso, Josias também produz panelas e vasos da mesma forma que sua mãe, utilizando apenas as mãos como meio de produção e acabamento, dessa maneira mantendo a essência da cerâmica caeteuara tradicional.

A produção dessas peças de barro inicia sua sistematização matemática desde o momento em que o ceramista pensa no que será produzido, posteriormente esse pensamento é modelado no formato das peças, sendo que: “o modelo não é objeto, obra arquitetônica ou tecnologia, mas projeto, esquema, lei ou representação que permite a produção ou reprodução ou execução dessa ação" (Biembengut, 2004, p. 16). O modelo que dona Maria e Josias utilizam é derivado de uma lógica interna, à medida que vão trabalhando as peças com as mãos, eles estabelecem as medidas de espessura das paredes das peças a serem fabricadas.

Após a modelagem que define o formato e as dimensões da peça que será produzida, a ceramista durante a etapa de alisamento da peça determina as proporções almejadas e por meio da observação contínua detecta quais sãos os erros que precisam ser corrigidos. A correção é feita no momento da finalização das peças. Como pontuado por Morin (2011, p.72): "é certo que todos os conceitos científicos extraídos da experiência social se emanciparam e transformaram. Nem por isso se separaram totalmente: força, trabalho, energia, ordem, desordem conservam seu cordão umbilical com a vida comum”.

Nesse sentindo, os saberes etnomatemáticos de dona Maria e Josias vão além do que os olhos podem ver, são desenvolvidos e aprimorados diariamente a partir de suas práticas como ceramistas. Seus pensamentos geométricos são construídos através de um processo 
onde o que foi pensado como peça e o que é produzido com as mãos é real em uma racionalidade matemática baseada apenas na prática como ceramista.

Esse saber etnomatemático é expresso com dimensões geométricas quando o ceramista pega a argila em qualquer formato e a transforma em uma esfera (Im 10) e como as mãos modela a transformando em uma figura plana (Im 11) sobre o eixo giratório ou sobre as próprias pernas, para posteriormente dar forma ao vazio a sua frente, e como mágica aos olhos de quem ver, uma estrutura de altura, largura e volume surge (Im 12 e $\operatorname{Im~13)~dando~}$ concretude a mais uma peça da tradicional cerâmica caeteuara.

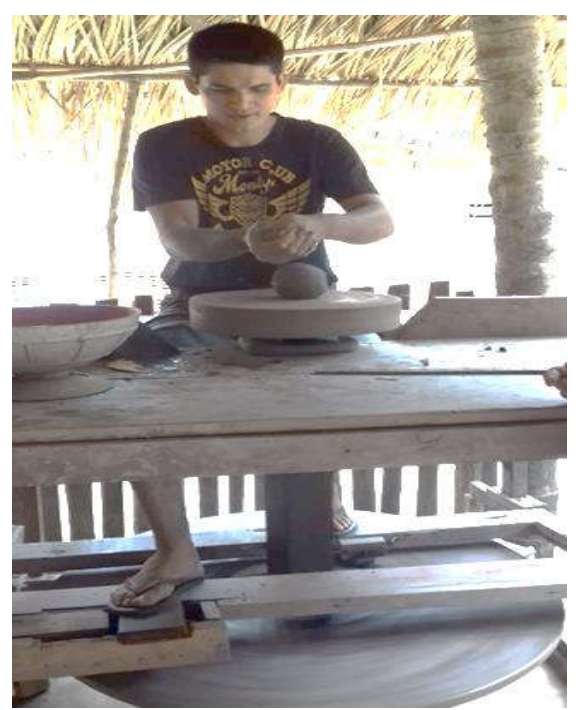

Im 9 Fonte - Acervo pessoal

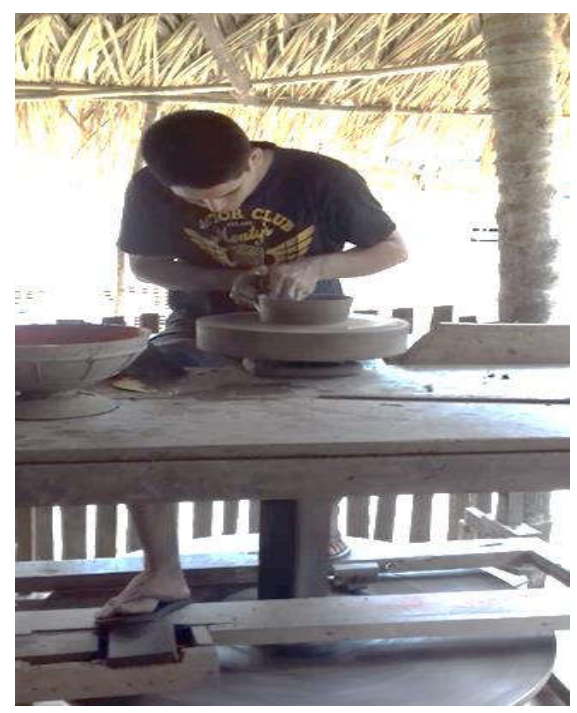

Im 11 Fonte - Acervo pessoal

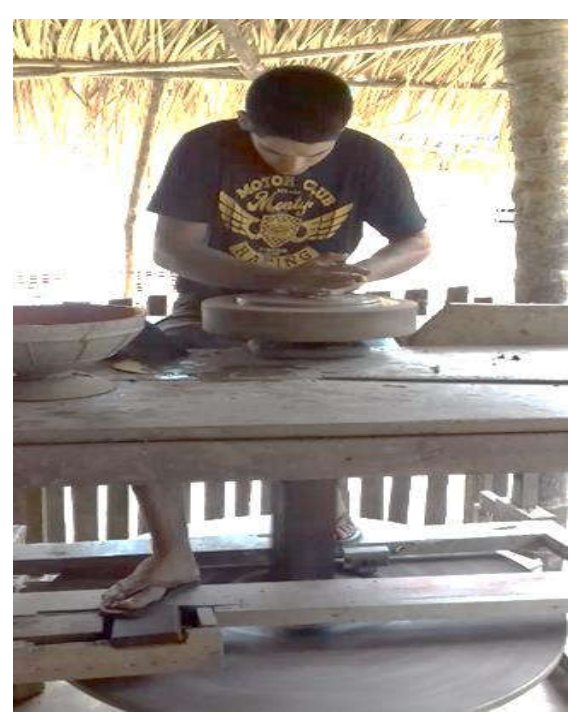

Im 10 Fonte - Acervo pessoal

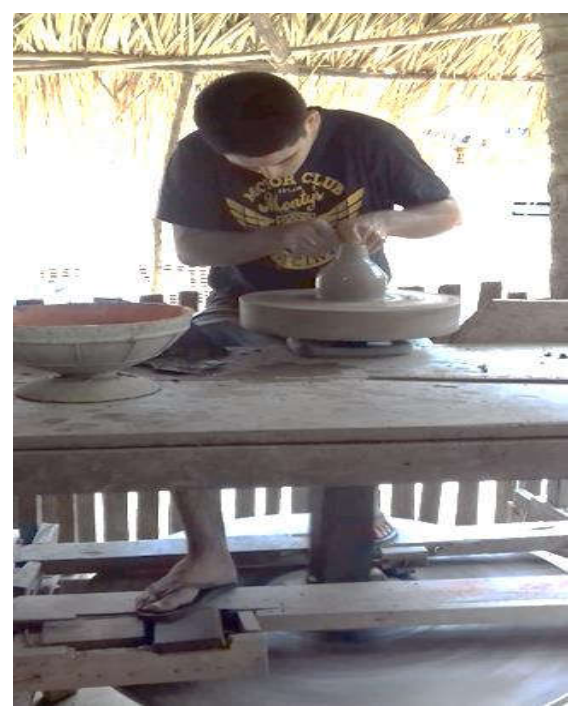

Im 12 Fonte - Acervo pessoal 
Assim, podemos perceber que tanto dona Maria, quanto Josias expressam ideias matemáticas que são baseadas na experimentação diária, suas peças possuem aspectos geométricos que são moldadas através de uma dualidade de sentidos (visão e tato) que permite moldar com as mãos as formas e modelos visualizados na mente.

Outro aspecto Etnomatemático observado na cerâmica caeteuara é a simetria, e para discutirmos sobre ela, analisaremos a seguir alguns ornamentos geométricos presentes. Nesses ornamentos, é possível perceber aspectos referentes ao conceito de simetria, referindo-nos principalmente à noção de harmonia existente em certas combinações e proporções regulares que expressam um pouco da estética matemática das formas geométricas estabelecidas.

Cabe ressaltar que antes de discutirmos os três tipos de movimentos rígidos presentes na cerâmica caeteuara, é importante explicarmos que quando analisamos a simetria presente nos vasos que são feitos através de um processo artesanal, à mão livre, em uma área normalmente curva (côncava ou convexa), não podemos exigir que estes possuam uma correspondência perfeita no rigor da matemática acadêmica, pois é normal que possuam algumas distorções que não são facilmente perceptíveis a olho nu, e serão consideradas desprezíveis neste trabalho, por se tratarem de desvios mínimos, impossíveis de não serem cometidos em trabalhos artesanais como esse.

Nas peças feitas por dona Maria observamos que em sua maioria costuma ter o mesmo acabamento feito pelos dedos de suas mãos ou com pequenos galhos de árvores que ela mesma tira, o que garante uma marca registrada da ceramista e caracteriza a cerâmica caeteuara tradicional feita na vila Cuera. Esse cuidado com os detalhes da peça de forma a garantir uma cobertura total nos remete aos conceitos de simetria, pois a "simetria não é um número nem um formato, é um tipo especial de transformação - uma maneira de mover um objeto. Se o objeto parecer o mesmo depois de movido, a transformação aí presente é uma simetria" (STEWART, 2012, p.9).

Durante a pesquisa em campo observamos que a preocupação maior de dona Maria é que suas peças não saiam tortas, "Sempre tomo muito cuidado, pra não ficar torto, porque se fica torto, com uma parte maior que a outra ela não senta direito" (dona Maria, informação verbal). E dessa forma podemos contemplar saberes etnomatemáticos ligados à simetria com pontos de translação, rotação e reflexão na mesma peça, visto que o raciocínio matemático de dona Maria é totalmente visual e prático. Usando uma peça criada por dona Maria podemos exemplificar onde ocorrem esses saberes etnomatemáticos ( $\operatorname{Im} 13)$. 


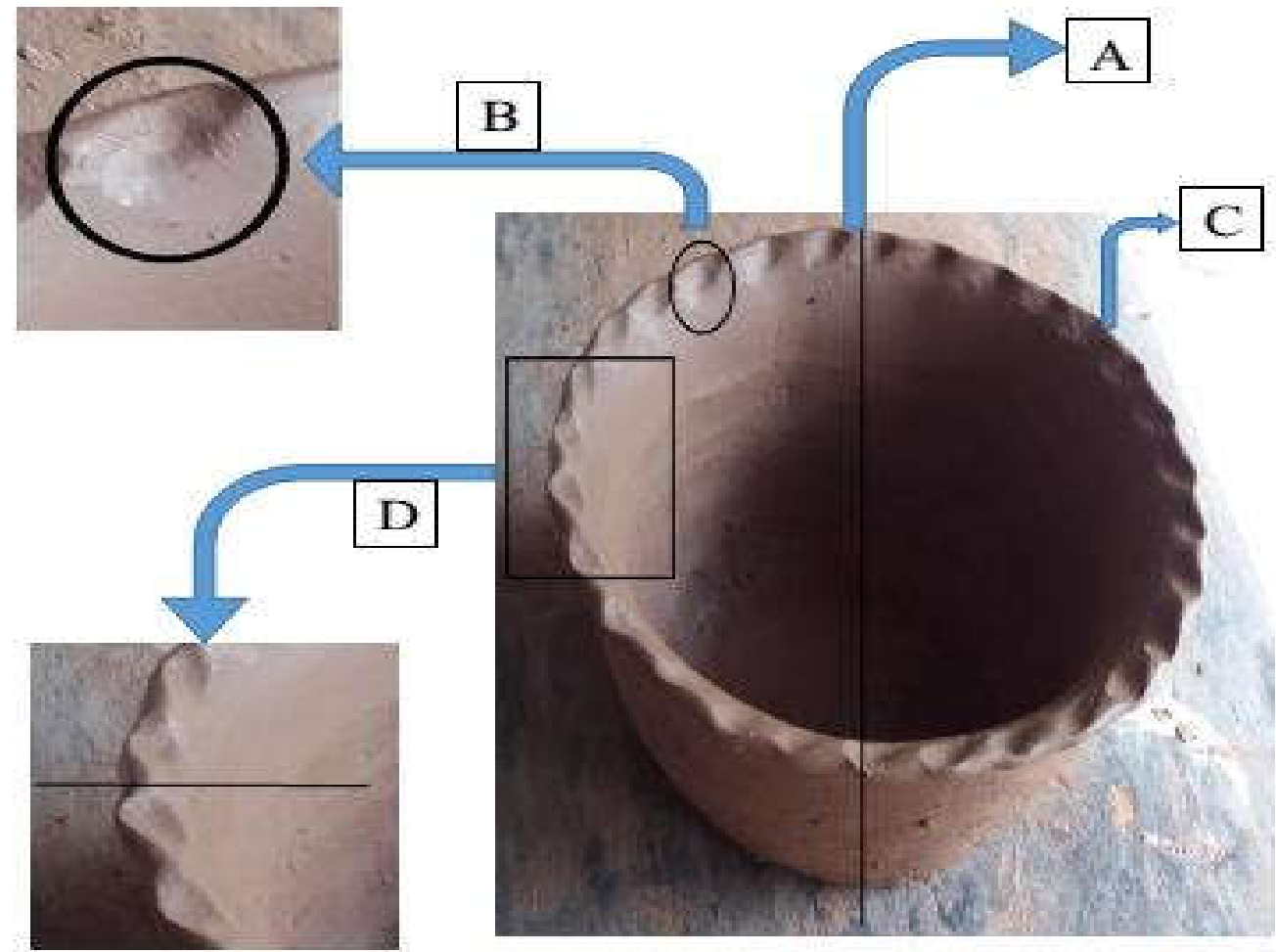

Im 13 Fonte - Acervo Pessoal

No ponto identificado como "A" encontramos o eixo de simetria que nos indica o quanto o saber tradicional da cerâmica caeteuara foi sendo aprimorado com o passar dos anos. No ponto "B" identificamos que a artesã usou várias vezes o recurso da translação para construir a sua peça, através de uma modelagem feita com os dedos da mão, realizou uma volta completa em torno da peça, de tal forma que não conseguimos perceber em qual parte ele começou a fazer as pequenas marcações, esse padrão encontrado destacamos no recorte ao lado da imagem. Da mesma forma observamos em que do ponto "B" ao ponto " $\mathrm{C}$ " temos um movimento simétrico de rotação, todavia, é importante destacarmos, que ao observarmos a correspondência simétrica ponto-a-ponto, concluiremos que na realidade esses dois pontos simbólicos não são perfeitamente simétricos, porém, devemos levar em consideração, como explicamos anteriormente, que essas peças foram feitos à mão livre, sem ajuda de grandes recursos em uma superfície côncava, o que dificulta bastante o trabalho. Ainda analisando a peça construída por dona Maria observamos no ponto " $D$ " o movimento simétrico de reflexão, onde bem é caracterizada através do eixo de simetria traçado no recorte da imagem ao lado, representado pela linha tracejada, assim podemos visualizar que a parte superior parece refletir a parte inferior. 
Essa simetria costuma estar presente na maioria das peças de dona Maria, visto que ela já estabeleceu um padrão para desenvolver seu ofício, onde os saberes etnomatemáticos estão impressos em diversos momentos e formatos.

Nessa mesma ótica observamos as peças construídas por Josias, tentando junto ao mesmo entender o raciocínio matemático por trás de suas peças. O ceramista Josias cria peças de diversos tamanhos e formatos ( $\operatorname{Im} 14$, Im 15 e Im 16), e que mesmo com auxilio de ferramentas que ajudam na fabricação das peças, suas atribuições simétricas são realizadas a "olho nu", colocando a visão como instrumento principal de medida.

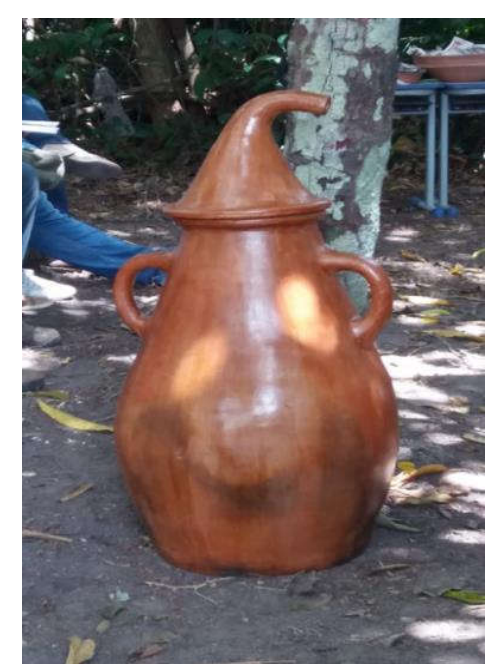

Im 14 Fonte - Acervo pessoal

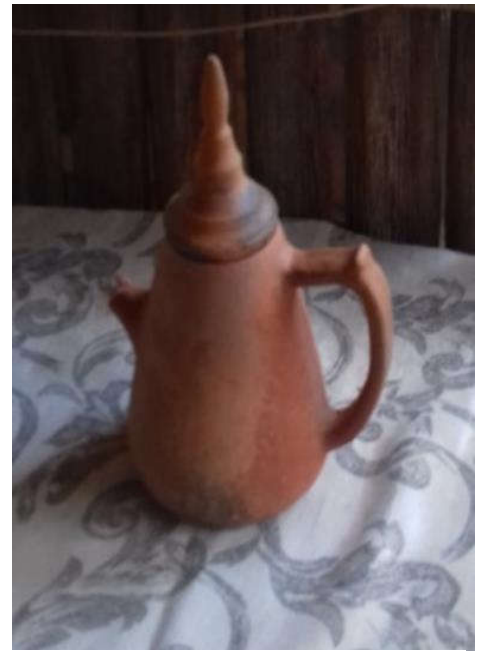

Im 15 Fonte - Acervo pessoal

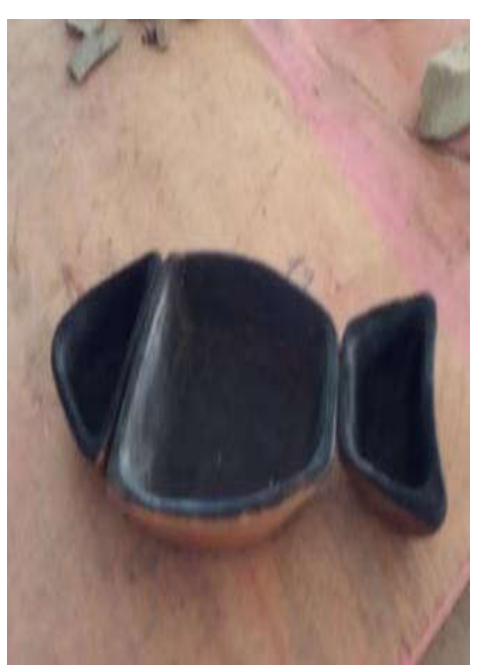

Im 16 Fonte - Acervo pessoal

Josias explica que mesmo com auxilio de suas ferramentas, o acabamento ainda continua artesanal e que o mesmo só utiliza as ferramentas quando tem uma encomenda muito grande de peças, "eu gosto mesmo é de pegar na argila e ir construindo as coisas, assim me sinto melhor, porque foi desse jeito que aprendi com minha mãe" (Josias, informação verbal). $\mathrm{O}$ ceramista desenvolveu novas metodologias para construir suas peças e isso lhe proporcionou criar peças com formatos que só ele constrói na região. Com auxílio de suas mãos Josias vai construindo e reconstruído seus saberes.

Observamos que Josias expõe saberes etnomatemáticos relacionados à simetria quando conseguimos visualizar os padrões simétricos construídos por ele, mesmo que isso para ele seja apenas o controle para que suas peças não saiam tortas. Josias nos explica que "Eu geralmente visualizo a peça primeiro em minha mente, dormindo ou acordado, dessa forma já tenho calculado na mente mesmo, o tamanho da peça, sua largura, e quanto de barro vou usar. (...) aí depois eu só tenho cuidado de construir com as mãos a mesma peça que vi na 
mente" (Informação verbal). Nessa perspectiva, ele constrói suas peças seguindo padrões simétricos que são estabelecidos primeiro em sua mente e, posteriormente, continuados com suas mãos no barro como podemos observar no esquema a seguir (Im 17).

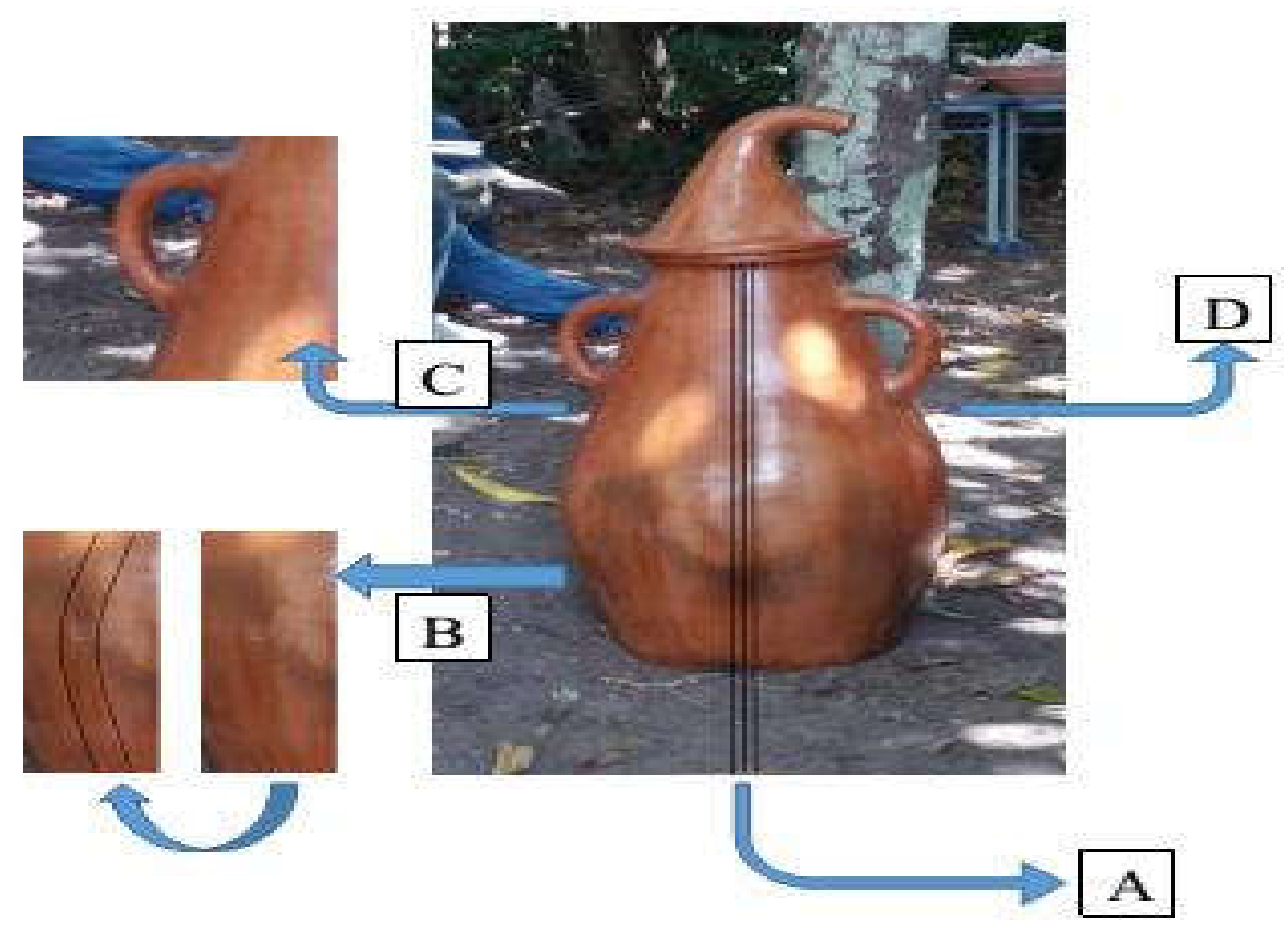

Im 17 Fonte - Acervo pessoal

A partir do esquema formado encontramos relações simétricas presentes no saber etnomatemático de Josias, no ponto "A" conseguimos estabelecer o eixo de simetria, parte muito importante no processo de construção da peça, "se os dois lados da peça não ficarem iguais a peça fica bamba e não fica em pé direito " (Josias, informação verbal) e desse modo as noções de simetria visualizadas na mente do ceramista são expostas na peça. No ponto "B" observamos o padrão de translação estabelecido pelo ceramista, esse padrão em formato de curva (parábola) se repete e completa uma volta completa ao redor da peça, dando um efeito harmônico em toda a estrutura da cerâmica. No ponto " $C$ " encontramos um movimento de rotação que partindo do raio que se origina no eixo simétrico central se estende até o ponto "D", onde por sua vez o ponto " $D$ " apresenta uma simetria de reflexão, que está bem caracterizada através do eixo de simetria representado pela linha tracejada. Este tipo de simetria é bem comum na cerâmica caeteuara, pois como o próprio ceramista Josias 
(Informação verbal) comenta, "sempre que construo minhas peças, tento imaginar e construir os dois lados como se fosse o mesmo, assim eu já sei de cabeça a medida de um lado e do outro e o formato também".

De acordo com o elucidado acima, as explicações de família Furtado sobre suas peças, mostram que o ceramista busca essa harmonia própria de simetria, a fím de construir uma peça que tenha a mesma distância do centro para as laterais, se preocupando com as combinações perfeitas tanto de largura como de altura que mesmo sem acessórios como calculadora, compasso, fita métrica ou algo do segmento, o impede de exercer seu oficio e expressar saberes etnomatemáticos de diversas origens em seu cotidiano.

\section{CONSIDERAÇÕES FINAIS}

Durante nossas pesquisas observamos que os artesãos acompanhados na pesquisa não possuem um conceito formado de geometria ou simetria, de translação, de rotação ou de reflexão, porém isso não os impede de construir peças de diversas formas, tamanhos e utilidades. As racionalidades matemáticas ligadas à geometria são estabelecidas primeiro em sua mente para posteriormente serem moldadas em cada peça, mostrando que os saberes etnomatemáticos dos ceramistas estão diretamente ligados aos seus sentidos, já os conceitos de simetria são expressos por eles de forma intuitiva, no momento em que vão construindo suas peças, pois para conseguirem construir cada detalhe da cerâmica caeteuara, vão realizando voltas completas na peça, normalmente imaginam o melhor tamanho do modelo visto em sua mente, e nessa lógica matemática própria do ceramista as dimensões e eixos de simetrias também já vão sendo construídas e por fim produzem uma peça onde um lado praticamente reflete o outro. O ceramista ainda expressa noções de proporção e cálculos mentais bem elaborados, pois apenas se utilizando da visão e do tato consegue determinar a quantidade de argila que cada peça necessita, assim como a quantidade de peças que uma porção de argila pode se transformar, mostrando que seus saberes etnomatemáticos vão além de conhecimentos geométricos e simétricos e que possuem uma forma própria de serem construídos e repassados.

\section{REFERÊNCIAS}

ALMEIDA, Maria da Conceição de. Complexidade, saberes científicos, saberes da tradição. São Paulo: Livraria da Física. 2010. 
ASCHER, M. and R. Ethnomathematics. History of Science. ASCHER, 1986.

BARTON, B. Dando sentido a Etnomatemática: Etnomatemática fazendo sentido. IN: RIBEIRO: José Pedro Machado; DOMITE, Maria do Carmo Santos; FERREIRA, Rogério(organizadores). Etnomatemática: papel, valores e significado. São Paulo: Zouk, 2004.

BIEMBEGUT, Maria Salett. Modelagem Matemática \& implicações no ensino e na aprendizagem da Matemática. Blumenau, 2 Ed. Edfurb. 2004.

D’AMBRÓSIO, U. Etnomatemática: Um Programa. Educação Matemática em Revista, Blumenau, n. 1, p. 5-11, 1993.

D’AMBROSIO, Ubiratan. Etnomatemática. São Paulo: Editora Ática, 1998.

D’AMBROSIO, Ubiratan. Sociedade, cultura, matemática e seu ensino. São Paulo: Educação e Pesquisa, 2005.

D'AMBROSIO, Ubiratan. Etnomatemática: Elo entre as tradições e a modernidade. 3 ed. Belo Horizonte: Autêntica, 2009. 112 p.

D’AMBROSIO, Ubiratan. Etnomatemática e Educação. In: KNIJNIK, Gelsa. et all (orgs). Etnomatemática: currículo e formação de professores. Santa Cruz do Sul: Edunisc, 2010.

D'AMBRÒSIO, Ubiratan. Etnomatemática: elo entre as tradições e a modernidade. Belo Horizonte: Autêntica Editora, 2011.

MORIN, Edgar. O Método 4: As ideias: vida, costumes, organização. 6 ed. Porto Alegre: Sulina. 2011.

FARIAS, Carlos Aldemir. MENDES, Iran Abreu. As culturas são as marcas das sociedades humanas. In: MENDES, Iran Abreu. FARIAS, Carlos Aldemir (Org.). Práticas Socioculturais e Educação Matemática. São Paulo: Livraria da Física. 2014.

FERREIRA, E. S. Por uma Teoria da Etnomatemática. Bolema, Rio Claro, v.22, p.30- 35, 1991.

FIORIN, José Luiz. Linguagem e Ideologia. 6º Edição, São Paulo: Editora Ática, 1998.

GERDES, P. Sobre o conceito de Etnomatemática. [S.1.], 1989. Tradução da primeira parte da introdução ao livro Estudos Etnomatemáticos, em alemão, ISP (Maputo) - KMU (Leipzig).

GERDES, Paulus. Da etnomatemática a arte-design e matrizes cíclicas. Horizonte: Autêntica editora, 2010.

GERDES, Paulus. Geometria Sona de Angola. Volume 2: Explorações educacionais e matemáticas de desenhos africanos na areia. ISTEG. Belo Horizonte. Boane, Moçambique. 2014.

KNIJNIK, Gelsa. Pesquisa em Etnomatemática: apontamentos sobre o tema. In: Anais do Congresso Brasileiro de Etnomatemática. 3. 2008. Niterói. 2008. 
MIARKA, Roger. Etnomatemática: do ôntico ao ontológico. 2011. 427 f. Tese (Doutorado em Educação Matemática). Instituto de Geociências e Ciências Exatas da Universidade Estadual Paulista Júlio de Mesquita Filho. Rio Claro. 2011.

MOREIRA, Darlinda. Etnomatemática e mediação de saberes matemáticos na sociedade global e multicultural. In: Anais do Congresso Brasileiro de Etnomatemática. 3. Niterói. 2008.

ROSA, Milton; OREY, Daniel Clark. Aproximações da Etnomatemática com o programa de pesquisa de Lakatos. In: Encontro de Etnomatemática do Rio de Janeiro,1, 2014. Anais do Encontro de Etnomatemática do Rio de Janeiro, 2015.

STEWART, Ian. Uma História da Simetria na Matemática. Rio de Janeiro: Zahar, 2012.

TAVARES, Margarida M. R. et al. Diagnóstico do Potencial Turístico. Municípios de Bragança, Augusto Corrêa e Tracuateua. Estado do Pará: CPRM/ Primaz, Seicom, 1998.

VERGANI, Teresa. Matemática \& Linguagem. Pandora Edições, Imagem e Comunicação. Lisboa: Largo da Graça, 2002.

VERGANI, Teresa. Educação Etnomatemática: o que é?. Natal: Flecha do tempo, 2007. 